\title{
Valores hematológicos, proteínas plasmáticas totais e fibrinogênio do cavalo crioulo - suas variações em relação ao sexo, idade e manejo*
}

\author{
Hematological values, plasma protein and fibrinogen \\ of criollo horse - their variation with sex, age and management \\ Angela Patricia Medeiros Veiga, Sonia Terezinha dos Anjos Lopes, \\ Carina Franciscato, Luis Sérgio Segala de Oliveira \& Luciana Paula Merini
}

\begin{abstract}
RESUMO
A criação de eqüinos da raça Crioula vem crescendo em todo Brasil nos últimos anos, porém ainda há uma escassez de informações sobre valores hematológicos em relação a esta raça. O presente trabalho teve como objetivos verificar as diferenças devidas ao sexo, idade, atividade e estado gestacional quanto ao hemograma, proteínas plasmáticas totais e fibrinogênio para a raça eqüina Crioula. Para tanto, tais parâmetros hematológicos foram analisados em 142 eqüinos Crioulos, divididos em quatro grupos: grupo um ( $n=26)$ - animais menores de um ano de idade (entre 4 e 9 meses); grupo 2 ( $n=39$ ) - animais maiores de dois anos (entre dois e 15 anos) a campo; grupo 3 (n=31) - animais maiores de dois anos (entre 2 e 15 anos), cuja rotina diária incluía exercícios físicos; grupo 4 ( $n=46)$ - fêmeas gestantes. A partir da análise de variância (ANOVA) e teste de Tukey, verificaram-se diferenças inerentes a grupos e sexos. As diferenças em relação ao grupo foram para as variáveis hematócrito, hemoglobina, VCM, CHCM, leucócitos totais, neutrófilos segmentados, eosinófilos, basófilos, monócitos, linfócitos, fibrinogênio e PPT; inerente ao sexo, para VCM e neutrófilos segmentados. A comparação dos parâmetros estudados com os de outras raças e populações eqüinas compelidos na literatura indicou que a maioria dos valores não é similar àquelas, não devendo os últimos ser utilizados como padrões para a raça.
\end{abstract}

Descritores: hematologia, valores de referência, cavalos Crioulos, veterinária.

\section{ABSTRACT}

Criollo horse breeding has shown a significant improvement in the last years, but there is still a lack of information about this breed. Because of what was exposed, this study had the aim to determine the Criollo variations on hemogram, plasma proteins, and fibrinogen, due to sex, age, activity and pregnancy status. To perform this, such hematological parameters were evaluated in 142 Crollo horses, grouped into four categories: G1 ( $\mathrm{n=26}$ ) - animals under one year-old (4 to 9 months); G2 (n=39) - animals in field, above two years-old ( 2 to 15 years-old); G3 ( $n=31$ ) - animals above two years-old (2 to 15 years-old), submitted to diary exercises; $\mathrm{G} 4(\mathrm{n}=46)$ - pregnant mares. We verified differences among groups and sexes. Differences about group were for PCV, hemoglobin, MCV, MCHC, WBC, segmented, basophils, eosinophils, monocytes, lymphocytes, fibrinogen, and plasma proteins. About sex, they were for MVC, and segmented. Comparison between studied parameters with other horse breeds and populations observed in literature showed that most values are not similar and they must not be used as pattern to this breed.

Key words: hematology, reference range, Criollo horse, veterinary. 


\section{INTRODUÇÃO}

A criação crioula está se desenvolvendo cada vez mais no país. Trata-se de uma raça nacional rústica, empregada tanto no trabalho rural como em competições [1]. Devido a sua importância, a criação desta raça tem se disseminado, não só pela América Latina, mas também pela Europa, com alguns países tendo sua associação de criadores de cavalos crioulos (ABCCC). Apesar disso, escassas são as informações a respeito de padrões hematológicos de referência para a raça [2].

O hemograma, as proteínas plasmáticas totais e o fibrinogênio são exames amplamente utilizados na clínica médica eqüina, porém, se comparados a valores de referência que não se enquadram às características pertinentes ao animal em questão, poderão resultar em diagnósticos errôneos. Sabendo-se que os padrões de referência são específicos para a idade, raça, disposição física, localização geográfica, estado reprodutivo e metodologia laboratorial, objetiva-se a determinação das alterações hematológicas entre as variáveis estudadas, relacionando-as a mudanças fisiológicas que ocorrem em tais categorias de animais, devido a: idade, sexo, manejo e estado gestacional [5,7]. O presente estudo também teve como objetivo verificar se a prática diária tem influência sobre as mensurações hematológicas, não como alterações decorrentes da contração esplênica, mas no animal atleta por si só.

\section{MATERIAL E MÉTODOS}

Foram utilizados 142 eqüinos da raça Crioula, desverminados e submetidos a exame clínico previamente à colheita. Os animais foram divididos em quatro grupos, de acordo com a idade, atividade ou estado gestacional. Os grupos formados foram os seguintes: GRUPO 1 - Potros até um ano de idade $(\mathrm{n}=26)$; GRUPO 2 - Cavalos adultos, entre 2 e 15 anos, machos e fêmeas, em regime de atividade livre $(n=39)$; GRUPO 3 - Animais adultos, entre 2 e 15 anos, machos e fêmeas, em treinamento ( $\mathrm{n}=31$ ); GRUPO 4 - Éguas gestantes $(n=46)$. Os animais eram provenientes de propriedades da região central do Rio Grande do Sul.

De cada animal foram colhidos $5 \mathrm{ml}$ de sangue, sempre no período da manhã, por meio de punção da jugular em tubo de colheita a vácuo ${ }^{1}$ com anticoagulante EDTA (ácido etilenodiaminotetracético, sal potássico) a $10 \%$ (em solução aquosa), para a realização de hemograma, proteínas plasmáticas totais (PPT) e fibrinogênio. A hematimetria e leucometria total foram realizadas em contador semi-automático de cé- lulas $^{2}$ e o diferencial leucocitário por microscopia ótica. A determinação da proteína plasmática total foi realizada por meio da técnica de refratometria ${ }^{3} \mathrm{e} o$ fibrinogênio pela técnica de aquecimento a $56^{\circ} \mathrm{C}$ [5]. Todos os princípios éticos recomendados quanto à utilização de animais em experimentos foram observados (Colégio Brasileiro de Experimentação Animal).

Para a análise estatística, utilizou-se o programa estatístico SAS ${ }^{4}$. Através da análise de variância (ANOVA) e do teste de Tukey pôde-se determinar as diferenças significativas entre sexos e grupos, considerando-se significância de 5\%. Para a análise, os grupos foram agrupados de acordo com características semelhantes, e determinadas as diferenças entre os grupos. Diferenças etárias foram determinadas comparandose potros com adultos a campo; diferenças quanto à atividade foram analisadas comparando-se adultos a campo com adultos em treinamento; diferenças quanto à gestação foram avaliadas comparando-se gestantes com não gestantes; em um segundo momento, foram determinadas diferenças entre animais adultos em repouso e em treinamento; quanto ao sexo, analisaram-se em conjunto os grupos 1,2 e 3 , sendo as gestantes excluídas desta análise. Desta forma, foram geradas cinco categorias de animais: jovens, adultos, animais em repouso, animais em treinamento e gestantes.

\section{RESULTADOS}

Os resultados obtidos poderão ser verificados nas Tabelas 1, 2, 3 e 4. Quanto à idade (animais jovens $\mathrm{X}$ adultos a campo), os potros apresentaram maiores valores de PPT (Tabela 1), fibrinogênio, leucócitos totais, neutrófilos segmentados, monócitos e linfócitos (Tabela 2), enquanto que os adultos apresentaram maiores valores de hemoglobina, hematócrito e VCM (Tabela 1). Analisando-se o estatus gestacional, a gestação causou um aumento nos leucócitos totais e basófilos (Tabela 2), e uma diminuição no VCM (Tabela 1). Foram observadas alterações inerentes à atividade física (adultos em treinamento $\mathrm{X}$ adultos a campo). Animais em treinamento apresentaram maiores mensurações de PPT (Tabela 1), enquanto que animais em repouso apresentaram maiores valores de VCM, CHCM (Tabela 1) eosinófilos e basófilos (Tabela 2). As diferenças encontradas em relação ao sexo foram: machos apresentaram maiores valores de CHCM, enquanto que fêmeas apresentaram maiores valores de VCM (Tabela 3) e neutrófilos segmentados (Tabela 4). 


\section{DISCUSSÃo}

Demonstra-se uma diferença entre os valores eritrocitários de cavalos crioulos e outras raças, o que nos faz enfatizar a necessidade imediata de que os valores aqui descritos estejam à disposição de clínicas, hospitais e laboratórios [5].

O grupo 1 apresentou valores mais baixos para hemoglobina e hematócrito (Tabela 1), coincidindo com dados reportados em Crioulos, sendo essas mudanças explicadas pela hemodiluição e baixo estatus ferroso frequiente em animais jovens [2,7]. Os valores de hemoglobina e hematócrito encontrados no presente estudo (Tabela 1) permaneceram abaixo dos valores referenciados, exceto os valores máximos de hematócrito para o grupo 3, que estão mais altas que os citados pelo autor [5]. Os valores determinados para a mesma raça e região geográfica também foram mais elevados do que os do presente estudo [2]. Outros autores verificaram valores de hematócrito e hemoglobina semelhantes aos aqui descritos, em se tratando de éguas gestantes Pantaneiras [9].

Os dados encontrados para hematócrito e hemoglobina, com exercício físico contrariam os achados estudos em que se utilizou PSI e Quarto de Milha [3,8]. Não foram verificadas diferenças com o exercício físico, tornando evidente que este aumento se deu naqueles experimentos, devido a alterações hidro-eletrolíticas decorrentes de perdas metabólicas.

\begin{tabular}{|c|c|c|c|c|c|c|c|}
\hline Grupo & $\mathbf{N}$ & $\begin{array}{l}\text { Eritrócitos } \\
\text { (x10 } / \mu \mathrm{L})\end{array}$ & $\begin{array}{l}\text { Hemoglobina } \\
(\mathrm{g} / \mathrm{dL})\end{array}$ & $\begin{array}{c}\text { Hematócrito } \\
(\%)\end{array}$ & $\begin{array}{l}\text { VCM } \\
\text { (fL) }\end{array}$ & $\begin{array}{c}\underset{(\%)}{\mathrm{CHCM}} \\
\text { (\%) }\end{array}$ & $\begin{array}{l}\text { PPT } \\
\text { (g/dL) }\end{array}$ \\
\hline Potros & 26 & $\begin{array}{c}7,44^{\mathrm{a}^{*}} \\
(5,74-8,90) \\
\pm 0,908\end{array}$ & $\begin{array}{c}10,65^{b} \\
(7,6-13) \\
\pm 1,269\end{array}$ & $\begin{array}{c}31,9^{b} \\
(23-39) \\
\pm 3,73\end{array}$ & $\begin{array}{c}43,0^{c} \\
(37,23-52,37) \\
\pm 3,47\end{array}$ & $\begin{array}{c}33,35^{\mathrm{a}} \\
(33-36) \\
\pm 0,63\end{array}$ & $\begin{array}{c}8,15^{b} \\
(7,2-10,1) \\
\pm 0,509\end{array}$ \\
\hline Adultos a campo & 39 & $\begin{array}{c}7,48^{\mathrm{aA}} \\
(5,3-9,57) \\
\pm 1,04\end{array}$ & $\begin{array}{c}12,58^{\mathrm{aA}} \\
(9,3-16,1) \\
\pm 1,804\end{array}$ & $\begin{array}{c}37,5^{\mathrm{aA}} \\
(28-49) \\
\pm 4,93\end{array}$ & $\begin{array}{c}50,55^{\mathrm{aA}} \\
(40,5-61,53) \\
\pm 5,72\end{array}$ & $\begin{array}{c}33,45^{\mathrm{aA}} \\
(30,29-35,64) \\
\pm 1,09\end{array}$ & $\begin{array}{c}8,51^{1 \mathrm{aB}} \\
(7,5-10,1) \\
\pm 0,622\end{array}$ \\
\hline $\begin{array}{l}\text { Adultos em } \\
\text { treinamento }\end{array}$ & 31 & $\begin{array}{c}7,64^{\mathrm{A}} \\
(5,24-9,83) \\
\pm 1,19\end{array}$ & $\begin{array}{c}12,81^{\mathrm{A}} \\
(8,3-18,8) \\
\pm 2,21\end{array}$ & $\begin{array}{c}36,5^{\mathrm{A}} \\
(25-55) \\
\pm 6,48\end{array}$ & $\begin{array}{c}47,82^{\mathrm{B}} \\
(38,42-57,73) \\
\pm 5,03\end{array}$ & $\begin{array}{c}35,12^{\mathrm{B}} \\
(32,36-35,94) \\
\pm 1,20\end{array}$ & $\begin{array}{c}8,06^{A} \\
(7,4-9,4) \\
\pm 0,43\end{array}$ \\
\hline Gestantes & 46 & $\begin{array}{c}7,5^{\mathrm{a}} \\
(5,99-9,13) \\
\pm 0,84\end{array}$ & $\begin{array}{c}11,81^{\mathrm{a}} \\
(8,3-15,2) \\
\pm 1,46 \\
\end{array}$ & $\begin{array}{c}35,3^{a} \\
(25-46) \\
\pm 3,6\end{array}$ & $\begin{array}{c}47,32^{\mathrm{b}} \\
(38,5-56,7) \\
\pm 4,68 \\
\end{array}$ & $\begin{array}{c}33,16^{a} \\
(24,7-35,8) \\
\pm 1,39 \\
\end{array}$ & $\begin{array}{c}8,38^{\mathrm{ab}} \\
(8-10) \\
\pm 1,65\end{array}$ \\
\hline Total & 142 & 7,51 & 12 & 35,5 & 47,52 & 33,70 & 8,30 \\
\hline
\end{tabular}

"Letras diferentes indicam diferença significativa $(\mathrm{p}<0,05$; teste de Tukey).

Tabela 2. Valores médios, máximos, mínimos e desvios-padrão do leucograma e fibrinogênio de equinos da raça Crioula da região central do $\mathrm{RS}$, separados por grupo de atividade.

\begin{tabular}{|c|c|c|c|c|c|c|c|c|c|}
\hline Grupo & $\mathbf{N}$ & $\begin{array}{l}\text { Leucócitos Totais } \\
\qquad(/ \mu \mathrm{L})\end{array}$ & $\begin{array}{c}\text { Neut. Segm. } \\
(/ \mu L)\end{array}$ & $\begin{array}{l}\text { Baston. } \\
(/ \mu L)\end{array}$ & $\begin{array}{c}\text { Eosinófilos } \\
(/ \mu L)\end{array}$ & $\begin{array}{l}\text { Basóf. } \\
(/ \mu L)\end{array}$ & $\begin{array}{l}\text { Monóc. } \\
(/ \mu L)\end{array}$ & $\begin{array}{l}\text { Linfócitos } \\
\qquad(/ \mu \mathrm{L})\end{array}$ & $\begin{array}{l}\text { Fibrinog. } \\
\text { (g/dL) }\end{array}$ \\
\hline Potros & 26 & $\begin{array}{c}12950^{\mathrm{a}} \\
(6100-18900) \\
\pm 2698,6\end{array}$ & $\begin{array}{c}6111^{\mathrm{a}} \\
(2928-11172) \\
\pm 1847,4\end{array}$ & $\begin{array}{c}38,85^{\mathrm{a}} \\
(0-164) \\
\pm 61,16\end{array}$ & $\begin{array}{c}655,30^{\mathrm{a}} \\
(286,9-1043) \\
\pm 276,1\end{array}$ & $\begin{array}{c}34,8^{b} \\
(0-147) \\
\pm 58,46\end{array}$ & $\begin{array}{c}625,0^{a} \\
(0-1062) \\
\pm 233\end{array}$ & $\begin{array}{c}5817^{a} \\
(2806-11151) \\
\pm 2171,3\end{array}$ & $\begin{array}{c}407^{a^{*}} \\
(100-800) \\
\pm 190,8\end{array}$ \\
\hline Adultos a campo & 39 & $\begin{array}{c}9510^{\mathrm{bA}} \\
(5500-22500) \\
\pm 3178,9\end{array}$ & $\begin{array}{c}4844^{\mathrm{bA}} \\
(2250-11438) \\
\pm 1740,7\end{array}$ & $\begin{array}{c}32,13^{\mathrm{aA}} \\
(0-266) \\
\pm 67,87\end{array}$ & $\begin{array}{c}394,0^{\mathrm{aA}} \\
(0-1792) \\
\pm 380,5\end{array}$ & $\begin{array}{c}78,8^{\mathrm{bA}} \\
(0-274) \\
\pm 84,19\end{array}$ & $\begin{array}{c}131^{\mathrm{bA}} \\
(0-582) \\
\pm 148,3\end{array}$ & $\begin{array}{c}4063^{\mathrm{bA}} \\
(1197-19575) \\
\pm 3181,1\end{array}$ & $\begin{array}{c}317^{\mathrm{bA}} \\
(100-900) \\
\pm 133,4\end{array}$ \\
\hline $\begin{array}{l}\text { Adultos em } \\
\text { treinamento }\end{array}$ & 31 & $\begin{array}{c}9041^{\mathrm{A}} \\
(5700-13500) \\
\pm 1713,13\end{array}$ & $\begin{array}{c}4348^{A} \\
(2146-8505) \\
\pm 1270\end{array}$ & $\begin{array}{c}24,74^{\mathrm{A}} \\
(0-135) \\
\pm 39,45\end{array}$ & $\begin{array}{c}200,8^{\mathrm{B}} \\
(0-720) \\
\pm 197,4\end{array}$ & $\begin{array}{c}31,4^{\mathrm{B}} \\
(0-204) \\
\pm 56,59\end{array}$ & $\begin{array}{c}128^{A} \\
(0-408) \\
\pm 114,9\end{array}$ & $\begin{array}{c}4303^{A} \\
(2000-6102) \\
\pm 1239,1\end{array}$ & $\begin{array}{c}290^{A} \\
(100-600) \\
\pm 129,4\end{array}$ \\
\hline Gestantes & 46 & $\begin{array}{c}11919^{a} \\
(6900-24500) \\
\pm 3206,9\end{array}$ & $\begin{array}{c}5799^{\mathrm{ab}} \\
(2940-13965) \\
\pm 1952,8\end{array}$ & $\begin{array}{c}31,24^{\mathrm{a}} \\
(0-244) \\
\pm 63,7\end{array}$ & $\begin{array}{c}529,9^{a} \\
(0-1441) \\
\pm 350,6\end{array}$ & $\begin{array}{c}171,6^{a} \\
(0-1221) \\
\pm 230,4\end{array}$ & $\begin{array}{l}211^{\mathrm{ab}} \\
(0-945) \\
\pm 191,5\end{array}$ & $\begin{array}{c}5165^{\mathrm{ab}} \\
(2790-11022) \\
\pm 1976,4\end{array}$ & $\begin{array}{c}318^{b} \\
(100-600) \\
\pm 150,9\end{array}$ \\
\hline Total & 142 & 10818 & 5277 & 31,4 & 443 & 90,5 & 247 & 4794 & 328,7 \\
\hline
\end{tabular}

"Letras diferentes indicam diferença significativa ( $\mathrm{p}<0,05$; teste de Tukey). 


\begin{tabular}{|c|c|c|c|c|c|c|c|}
\hline Sexo & $\mathrm{N}$ & 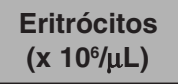 & $\begin{array}{l}\text { Hemoglobina } \\
(\mathrm{g} / \mathrm{dL})\end{array}$ & $\begin{array}{c}\text { Hematócrito } \\
(\%)\end{array}$ & $\begin{array}{l}\text { VCM } \\
\text { (fL) }\end{array}$ & $\begin{array}{c}\mathrm{CHCM} \\
(\%)\end{array}$ & $\begin{array}{l}\text { PPT } \\
\text { (g/dL) }\end{array}$ \\
\hline M & 43 & $\begin{array}{c}7,68^{a^{*}} \\
(5,7-9,83) \\
\pm 1,13\end{array}$ & $\begin{array}{c}11,9^{a} \\
(7,6-18,8) \\
\pm 2,18\end{array}$ & $\begin{array}{c}34,86^{a} \\
(23-55) \\
\pm 6,26\end{array}$ & $\begin{array}{c}45,45^{b} \\
(37,2-56,8) \\
\pm 5,32\end{array}$ & $\begin{array}{c}34,14^{a} \\
(30,9-36) \\
\pm 1,30\end{array}$ & $\begin{array}{c}8,18^{a} \\
(7,2-10,1) \\
\pm 0,48\end{array}$ \\
\hline $\mathrm{F}$ & 53 & $\begin{array}{c}7,40^{\mathrm{a}} \\
(5,24-9,57) \\
\pm 0,99 \\
\end{array}$ & $\begin{array}{c}12,3^{\mathrm{a}} \\
(9,3-16,1) \\
\pm 1,74 \\
\end{array}$ & $\begin{array}{c}36,34^{a} \\
(27-49) \\
\pm 4,93 \\
\end{array}$ & $\begin{array}{c}49,38^{\mathrm{a}} \\
(36,8-61,5) \\
\pm 5,78\end{array}$ & $\begin{array}{c}33,83^{\mathrm{b}} \\
(30,2-36) \\
\pm 1,35 \\
\end{array}$ & $\begin{array}{c}8,33^{\mathrm{a}} \\
(7,4-10,1) \\
\pm 0,6 \\
\end{array}$ \\
\hline Total & 96 & 7,54 & 12,1 & 35,6 & 47,4 & 33,98 & 8,25 \\
\hline
\end{tabular}

\begin{tabular}{|c|c|c|c|c|c|c|c|c|c|}
\hline Sexo & $\mathbf{N}$ & $\begin{array}{l}\text { Leucócitos Totais } \\
(/ \mu L)\end{array}$ & $\begin{array}{l}\text { Neut. Segm. } \\
(/ \mu \mathrm{L})\end{array}$ & $\begin{array}{l}\text { Baston. } \\
(/ \mu L)\end{array}$ & $\begin{array}{l}\text { Eosinófilos } \\
(/ \mu L)\end{array}$ & $\begin{array}{l}\text { Basóf. } \\
(/ \mu L)\end{array}$ & $\begin{array}{l}\text { Monóc. } \\
(/ \mu \mathrm{L})\end{array}$ & $\begin{array}{l}\text { Linfócitos } \\
(/ \mu L)\end{array}$ & $\begin{array}{l}\text { Fibrinog. } \\
\text { (g/dL) }\end{array}$ \\
\hline$M$ & 43 & $\begin{array}{c}9855,1^{\mathrm{a}} \\
(5500-16400) \\
\pm 2978\end{array}$ & $\begin{array}{c}4607,6^{\mathrm{b}} \\
(2146-9020) \\
\pm 1466,7\end{array}$ & $\begin{array}{c}36,3^{\mathrm{a}} \\
(0-164) \\
\pm 52,35\end{array}$ & $\begin{array}{c}510,8^{\mathrm{a}} \\
(0-1043) \\
\pm 249,7\end{array}$ & $\begin{array}{c}38,03^{a} \\
(0-225) \\
\pm 66,36\end{array}$ & $\begin{array}{c}391,1^{a} \\
(0-1062) \\
\pm 202,88\end{array}$ & $\begin{array}{c}4470,6^{a} \\
(1705-9849) \\
\pm 1964\end{array}$ & $\begin{array}{c}327,9^{a^{*}} \\
(100-800) \\
\pm 167,3\end{array}$ \\
\hline $\mathrm{F}$ & 53 & $\begin{array}{c}10643^{\mathrm{a}} \\
(7100-22500) \\
\pm 2950,5 \\
\end{array}$ & $\begin{array}{c}5368,6^{\mathrm{a}} \\
(2250-11438) \\
\pm 1854,1 \\
\end{array}$ & $\begin{array}{c}27,7^{\mathrm{a}} \\
(0-266) \\
\pm 58,9 \\
\end{array}$ & $\begin{array}{c}314,4^{\mathrm{a}} \\
(0-1792) \\
\pm 339,4 \\
\end{array}$ & $\begin{array}{c}62,68^{\mathrm{a}} \\
(0-274) \\
\pm 79,11 \\
\end{array}$ & $\begin{array}{c}161,4^{\mathrm{a}} \\
(0-670) \\
\pm 160 \\
\end{array}$ & $\begin{array}{c}4734,2^{\mathrm{a}} \\
(1197-19575) \\
\pm 2731 \\
\end{array}$ & $\begin{array}{c}337,7^{\mathrm{a}} \\
(100-900) \\
\pm 165,5 \\
\end{array}$ \\
\hline Total & 96 & 10249 & 4988,1 & 32 & 412,6 & 50,35 & 276,2 & 4602,4 & 332,8 \\
\hline
\end{tabular}

Os índices hematimétricos VCM e CHCM diferiram entre grupos (Tabela 1). As menores médias de VCM pertenceram aos potros, o que entra em desacordo com o já descrito [7], porém concorda com outros estudos [2,9]. A explicação proposta para estes dados é atribuída às baixas concentrações de ferro que se encontram nesta faixa, porém os animais avaliados em outro estudo, embora se enquadrassem na mesma raça e idade do presente estudo, apresentaram valores diferenciados para tais variáveis [2,7]. Houve diferença significativa para o VCM quanto ao sexo, ficando as fêmeas com as maiores médias, o que estaria associado a menores valores de hemácias, embora sem diferença estatística. Analisando-se o CHCM (Tabela 1), o grupo dos animais em atividade diferiu dos animais a campo, apresentando valores maiores, o que é explicado pelo elevado metabolismo, ainda que divergisse dos achados em eqüinos da raça Quarto de Milha [3].

Os valores de PPT (Tabela 1) encontrados foram maiores aos mensurados por alguns autores $[3,4,7]$. Estudos compararam três raças de eqüinos, detectando como única diferença os níveis de PPT, que foram maiores para os Árabes [11]. Os animais a campo apre- sentaram os maiores níveis de PPT enquanto os animais em treinamento apresentaram os menores, o que vai ao encontro a dados reportados [12]. Estes resultados foram contrários aos previamente propostos, pois a desidratação decorrente de perdas durante $o$ exercício é plenamente recuperada nas horas de descanso [3]. Os valores do grupo dos potros encontraramse mais baixos, demonstrando o estatus hídrico dos animais jovens, maior que o de adultos.

Presume-se que a diferença de fibrinogênio entre jovens e adultos tenha sido associada à maior quantidade de monócitos presente no grupo dos potros (Tabela 2), pois consoante alguns autores, as interleucinas produzidas pelos monócitos estimulam a produção e liberação de fibrinogênio [7]. Estes valores mostraram-se superiores aos previamente encontrados e inferiores aos relatados por outros autores [10], detectando-se diferença racial $[5,10]$. Os presentes valores estão dentro dos limites propostos [7].

A diferença na contagem total de leucócitos deu-se de forma que os grupos dos potros e das gestantes apresentaram as maiores contagens. Os valores mais elevados em potros por neutrófilos segmentados, 
monócitos e linfócitos, devido ao maior grau de excitabilidade dos animais jovens, concordando com dados relatados [9]. O oposto foi verificado quando se comparou o hemograma de eqüinos jovens com idosos, em que os idosos apresentaram uma menor contagem linfocitária [6]. O grupo de gestantes demonstrou este aumento na contagem leucocitária devido à grande quantidade de basófilos e neutrófilos. Embora sem diferença significativa, houve também um achado considerável de eosinófilos neste grupo, associando-se a isto a presença dos basófilos em altos níveis (Tabela 2). Conforme pesquisas anteriores, a liberação de histamina dos basófilos atrai os eosinófilos devido à presença, nestas células, da enzima histaminase, tornandoas células antagônicas [5]. Não houve diferença para esta variável entre sexos, demonstrando que ocorre devido a atributos gestacionais.

Diferenças sexuais foram detectadas em relação a neutrófilos, os quais foram maiores para as fêmeas (Tabela 4), portanto discordando dos achados de estudos anteriores em relação a cavalos Crioulos, em que machos apresentaram maiores valores leucocitários que fêmeas [2]. Uma maior contagem de basófilos em fêmeas foi reportada pelos mencionados autores em Crioulos.

\section{CONCLUSÕES}

Conclui-se que os eqüinos da raça Crioula, além de apresentarem valores hematológicos diferenciados aos descritos na literatura, mostram variações em relação à categoria animal à qual se enquadram, sejam devidas à idade, sexo, exercício físico ou estatus gestacional. Assim, tais características devem ser levadas em consideração quando da interpretação do hemograma, nesta raça.

\section{NOTAS INFORMATIVAS}

${ }^{1}$ Hemogard ${ }^{\circledR}$ K3, Labnew. São Paulo, Brasil.

${ }^{2}$ CELM 500 - Cia. Equipadora de Laboratórios Modernos. São Paulo, SP.

${ }^{3}$ Refratômetro ATTAGO, CO, USA.

${ }^{4} \mathrm{SAS}$, Software Estatístico, Cary / North Carolina, v2, version 6.08 .

\section{REFERÊNCIAS}

1 Affonso A. \& Correa S. 1992. Cavalo Crioulo: Uma História de Raça. Porto Alegre: Sagra, 210 p.

2 Almeida M.A.Z. \& Silva N.M. 1995. Determinação dos valores hematológicos normais do cavalo (equus caballus, linnaeus) da raça crioula. A Hora Veterinária. 15: 48-50.

3 Conceição M., Laposy C.B., Melchert A., Lopes R.S., Kohayagawa A. \& Takahira R.K. 2001. Hemograma e bioquímica sérica de eqüinos da raça quarto de milha antes e após o exercício. Veterinária Notícias. 7: 87-92.

4 Fagliari J.J. \& Silva S.L. 2002. Hemograma e proteinograma plasmático de eqüinos hígidos e de eqüinos acometidos por abdomen agudo, antes e após laparotomia. Arquivo Brasileiro de Medicina Veterinária e Zootecnia. 54: 559-567.

5 Jain N.C. 1993. Essentials of Veterinary Hematology. Philadelphia: Lea \& Febiger, 417 p.

6 McFarlane D., Sellon D.C., Gaffney D., Hedpeth V., Papich M. \& Gibbs S. 1998. Hematologic and serum biochemical variables and plasma corticotrophin concentration in healthy aged horses. American Journal of Veterinary Research, 59: 1247-1251.

7 Meyer D.J. \& Harvey J.W. 1998. Veterinary Laboratory Medicine: Interpretation and Diagnosis. 2nd edn. Philadelphia: W.B. Saunders Company, 373 p.

8 Raymond J.G., Douglas J.W. \& Clark M.S. 1994. Hemorheologic alterations induced by incremental treadmill exercise in thoroughbreds. American Journal of Veterinary Research. 55: 854-861.

9 Ribeiro C.R., Fagliari J.J., Galera P.D. \& Lacerda Neto J.C. 2002. Avaliação do hemograma de potras e de éguas gestantes da raça Pantaneira. XXIX Congresso Brasileiro de Medicina Veterinária (CONBRAVET). Anais do XXIX Congresso Brasileiro de Medicina Veterinária (Gramado, Brasil). 1:88.

10 Ribeiro C.R., Fagliari J.J., Galera P.D. \& Lacerda Neto J.C. 2002. Proteinograma sérico de eqüinos da raça pantaneira obtido por eletroforese em gel de agarose. XXIX Congresso Brasileiro de Medicina Veterinária. Anais do XXIX Congresso Brasileiro de Medicina Veterinária (Gramado, Brasil). 1:43.

11 Rubio M.D., Munoz A., Santisteban R., Tovar P. \& Castejon F.M. 1995. Comparative hematological study of two breeds of foals (Andalusian and Arab) subjected to exercise of progressive intensity. Journal of Veterinary Medical Science. 57: 311-315.

12 Santos S.A., Silva R.A.M.S., Azevedo J.R.M., Mello M.A.R., Soares A.C., Sibuya C.Y. \& Anaruma C.A. 2001. Serum electrolyte and total protein alterations in Pantaneiro horse during long distance exercise. $A r$ quivo Brasileiro de Medicina Veterinária e Zootecnia. 53: 81-89.

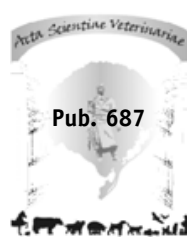

